Original Research Paper

\title{
Long Term Ageing Effect on Physical and Shear Strength Characteristics of Oil Contaminated Sandy Soils of Al- Ahmadi Field in Kuwait
}

\author{
${ }^{1}$ Humoud Melfi Aldaihani and ${ }^{2}$ Fahad A. Al-Otaibi \\ ${ }^{1}$ Full Time as Civil Engineering Consultant at Environment Affairs Department at Ministry of Public Works (MPW), \\ Kuwait, Part Time as Assistant Professor, Department of Civil Engineering, College of Technological Studies (CTS), \\ Public Authority for Applied Education and Training (PAAET), Shuwaikh, Kuwait \\ ${ }^{2}$ Associate Professor, Department of Civil Engineering, CTS, PAAET, Shuwaikh, Kuwait
}

Article history

Received: $31-10-2018$

Revised: 01-12-2018

Accepted: 01-04-2019

Corresponding Author: Humoud Melfi Aldaihani Department of Civil

Engineering, Civil Engineering Consultant at MPW, CTS,

PAAET, Kuwait

Email: hm.aldaihani1@paaet.edu.kw

\begin{abstract}
Serious environmental damage was caused to Kuwait when more than 600 oil wells were set alight following the 1991 Gulf War, leading to hydrocarbon contamination and a series of 'oil lakes' being created in the desert. The effects of these highly damaging actions are still detectable today, 27 years later. The main contribution of this paper is that the effects on the behavior of physical and shear strength properties of the Al-Ahmadi field sand brought about via the long-term ageing influence of hydrocarbon contamination will be explored, using the methodology of comparing contaminated and non-contaminated soil samples. For the purpose of this paper, nine samples, from more than 28 years' oil contaminated site, were subject to both physical and shear strength tests alongside hydrocarbon analysis using Gas Chromatograph Mass Spectrometer (GC-MS) testing. The results of these tests showed a notable increase in both the mean values of fines particles (from $7.8 \%$ to $11.8 \%$ ) and of gravel particles (from $5.8 \%$ to $27.8 \%$ ). These results clearly illustrate that the overall effect of the change in soil gradation was a poorer one. A reduction in strength was also observed in these tests, which possibly related to accumulation of particles within the soil layer leading to poorer grain size and to ageing effect that increase asphalting lead to weak bonding between particles.
\end{abstract}

Keywords: Hydrocarbon Contamination, Oil Lakes, Physical Properties of Oil-Contaminated Soil, Shear Strength Characteristics of OilContaminated Soil

\section{Introduction}

Located to the north-west of the Arabian Gulf, Kuwait has over 909 oil wells, which are distributed across ten oil fields, usually attributed as being north or south. There are 143 oil wells in the northern area, spread across oil fields including Bahra, Raudhtain, Ratga and Sabriay. In the southern region, the Greater Burgan oil field comprises the Burgan, Maqwa and Ahmedi fields and together with the other southern fields of Minagish, Umm Gudair and Wafra, the region has a total of 766 oil wells (Fig. 1) (Al-Duwaisan and Al-Naseem, 2011).

Aldaihani (2017) states that the destruction caused by 1991's Gulf War has led to serious environmental damage for Kuwait, with the formation of oil lakes and hydrocarbon contamination singled out as key factors. As noted by Al-Besharah (1991), Kuwait's desert was carpeted by serious oil leakages during the war, produced by the blazing destruction of the oil wells. When the oil fields were set alight, the fires generated gigantic plumes of black smoke, which then settled as deposits of tarcrete, tarmat and soot (El-Baz et al., 1994). It is estimated that 565 oil wells were set on fire while the wellheads of a further 74 wells were destroyed, causing them to overflow (Fig. 2). The ruined wellheads led to the creation of more than 300 oil lakes which covered more than 49 square kilometres across the fields of oil of the southern and northern areas (Al-Awadhi et al., 1996). According to Al-Duwaisan and Al-Naseem (2011) and Cho et al. (1997), nine of 
Kuwait's principal oil fields were affected by these toxic oil lakes: The Greater Burgan Field (Magwa, Burgan and Ahmadi Areas) together with Minagish, Wafra, Bahra, Ratga, Sabriyah, Umm Gudair and
Rawdhatain. These oil lakes were reported by AlAwadhi et al. (1992: 1993) to vary in shape and size, with an average depth of $0.3 \mathrm{~m}$, although some were as deep as $1.2 \mathrm{~m}$ (Fig. 2).

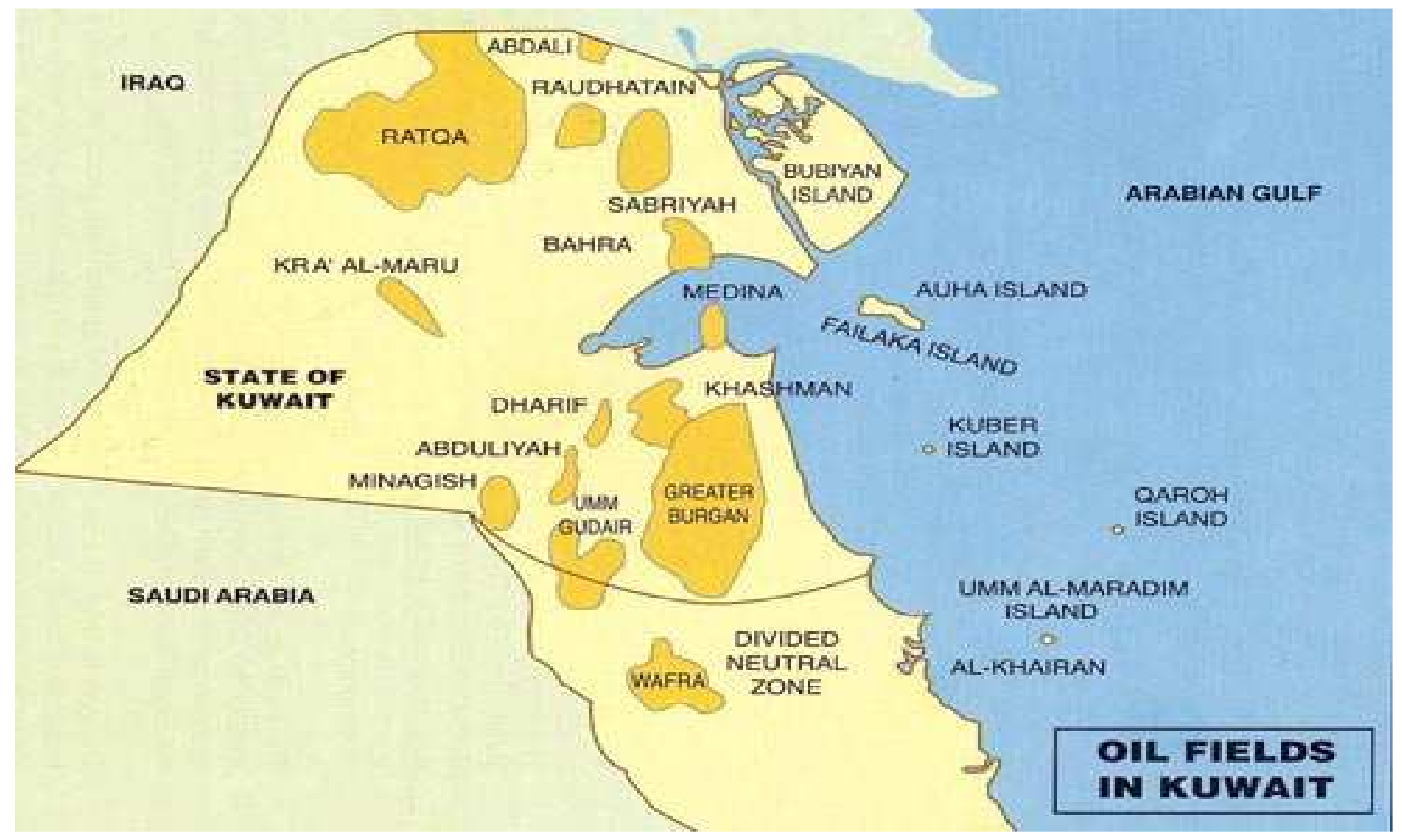

Fig. 1: Location of the Kuwait oil fields (Aldaihani et al., 2018)

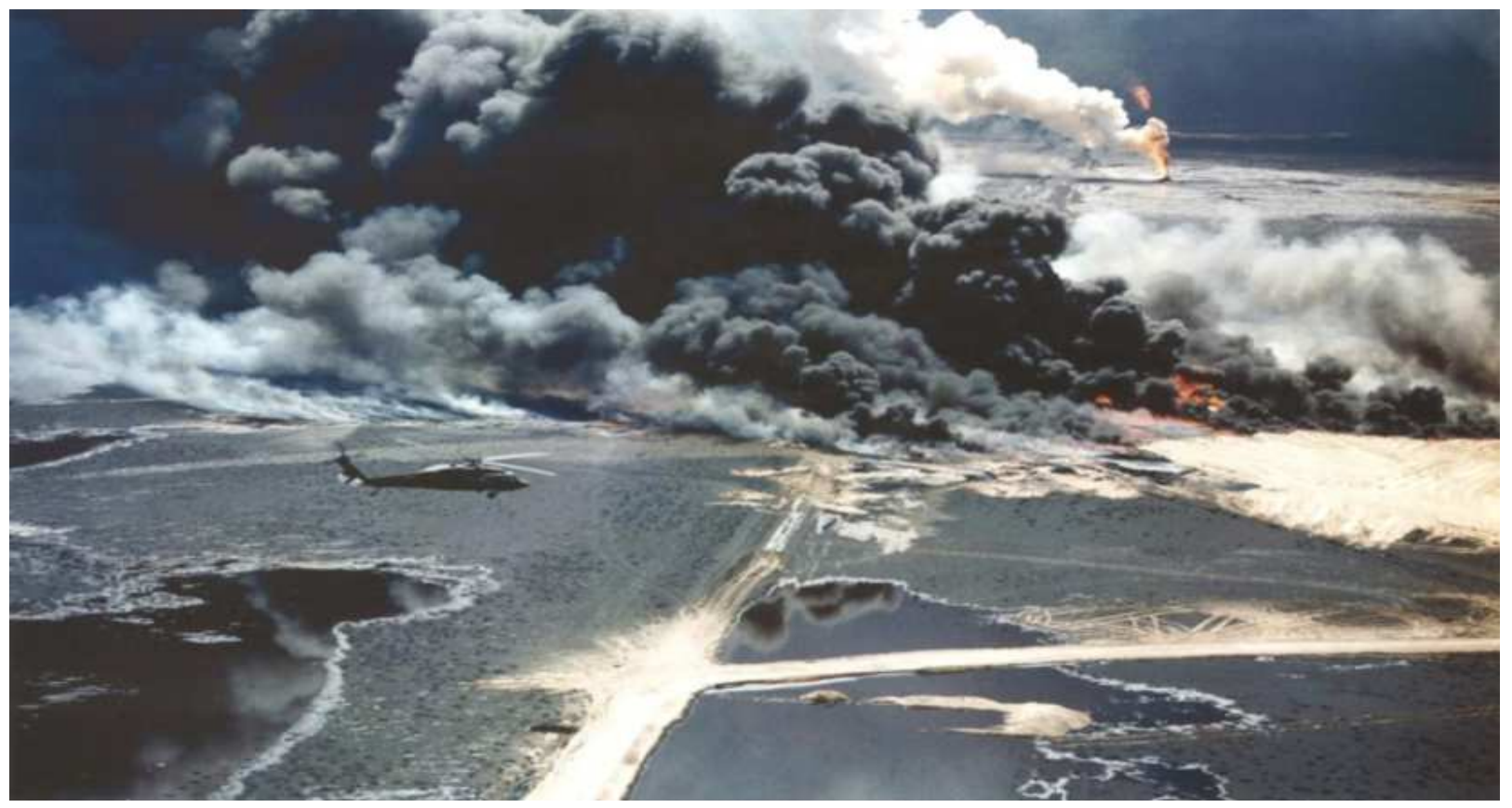

Fig. 2: Kuwait's ecosystem has suffered long-term damage as a result of oil lakes and fires (Aldaihani, 2017) 
Asem et al. (2016) recognise that oil spills cause large-scale contamination of soil, altering its geotechnical properties and furthermore Karkusha and Abdul Kareemb (2017) advise that soil contamination caused by oil spills (above certain levels) leads to the loss of some of the soil's geotechnical properties, to the detriment of structures built upon it. The effect of mixing different amount of oil to sand on its internal friction angle $(\varphi)$ was investigated by Khamehchiyan et al. (2007), Al-Sanad et al. (1995), Singh et al. (2009), Taqieddin (2017) and Shin et al. (1999).

Each of these researchers discovered that the $\varphi$ was decreased as a result of the action of oiling of oil, which reduced the contact among the particles. The shear strength tests were conducted directly after the addition of oil. In addition, they discovered that the $\varphi$ was additional reduced by increasing the oil content. Furthermore, it was also revealed that crude oil not only rises the sand cohesion but also has a powerful influence on the $\varphi$ of sand with regard to increasing the amount of oil (Al-Adili et al., 2017; Chaudhary and Singh, 2016).

Studies have been carried out to identify the geotechnical traits of the soil at different levels of crude oil contamination: $2 \%, 4 \%$ and $6 \%$ and how the contamination affected their ageing properties. Under laboratory conditions and based on testing immediately after the addition of oil to soil, Al-Sanad and Ismael (1997) reported a decreased angle in the samples' internal friction $(\varphi)$ values and the amount of this reduction was directly related to the amount of oil added. The mixed samples were then re-tested at set intervals to determine the effect of ageing, with evaluations taking place after four, twelve and twenty-six weeks. These tests took place in standard conditions. The results showed that evaporation of the volatile components had led to a reduced level of oil in the soil, while the internal friction values $(\varphi)$ in the samples had increased.

The author understands that there have been no studies to date that focus on the ageing effect of shear strength characteristics of oil-contaminated soil in Kuwait since 1990, although Al-Sanad and Ismael (1997) investigated the related subject of the ageing effect on the geotechnical aspect of contaminated soil. There were limitations to the Al-Sanad and Ismael study, as follows:

- The environmental conditions (including degradation and evaporation) were not considered, which in Kuwait's hot, arid climate would reduce the contaminant percentages

- The samples were mixed with different amounts of crude oil, which is considered an older method of testing

- The six-month testing period is considered shortterm and did not represent the actual harsh arid field conditions in Kuwait
The main contribution of this paper is to investigate the long-term ageing impact of hydrocarbon contamination resulting from oil spills in 1990. The arid environmental conditions in Kuwait (including degradation and evaporation) were not considered in all previous studies, which would reduce the contaminant percentages and contradict with the laboratory mixed samples.

The study will focus on the behavior of physical and shear strength properties of the Al-Ahmadi area sand of Kuwait by comparing contaminated and noncontaminated soil samples as there is deficiency in the investigation of oil contaminated sand behavior after immediately the leaking oil spills action in 1990.

\section{Site Location}

Based on the knowledge of the authors of the area (Aldaihani, 2017) and as oil soil pollution coupled with the rest oil lagoons are found in seven main fields, the selected sampling area borders the Al-Ahmadi Oil Field in the south of Kuwait. This location is close to the city as well as to the heavily populated city areas of Sabah Al-Salam, JeleebShuokh, Jaber Al-Ali and Al-Ahamdi which are likely to be further developed as demands for urban expansion increase. Due to this expansion, there is likely to be a need for several large-scale construction projects. The largest oil lake in Kuwait is also sited in this area, covering $25.6 \mathrm{~km}^{2}$ area with a soil volume $14,520,000 \mathrm{~m}^{3}$.

\section{Soil Sample Collection and Preparation}

Due to a lack of information about the site chosen for sampling, the square area of land $(40 \mathrm{~m} \times 40 \mathrm{~m})$ was divided into equal square sections measuring $20 \mathrm{~m}$ in $\mathrm{x}$ and $\mathrm{y}$ directions for both contaminated and noncontaminated testing (Fig. 3).

Nine sampling Trial Pits (T.Ps.) were chosen at a depth of $30 \mathrm{~cm}$ for each site, with nine disturbed samples of $3.5 \mathrm{~kg}$ being manually extracted from each to undergo chemical and physical tests. For a direct shear test, nine more soil cores were taken by pushing a hollow piece of stainless steel tubing into the ground, extracting the tube and removing the excess soil at each end, resulting in samples that measured $45 \mathrm{~mm}$ long and $25 \mathrm{~mm}$ wide (ASTM D 2937-04, 2008). Before putting the samples into bags, rubber seals were applied to each end and then each bag was sealed using plaster (Fig. 4). For testing, each sample was removed from its tube and placed into the shear box, where it could be compressed to ascertain its density and water content. Samples were preserved using the recognised methodology documented by ASTM D 4220-95, (2000) and Landon (2007). 


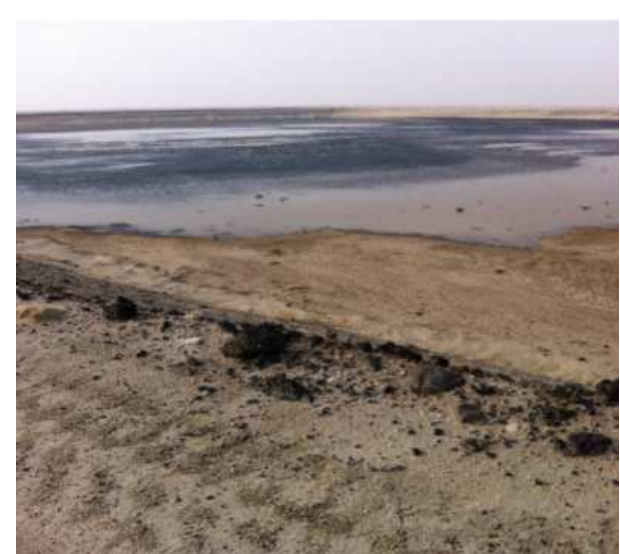

(A)

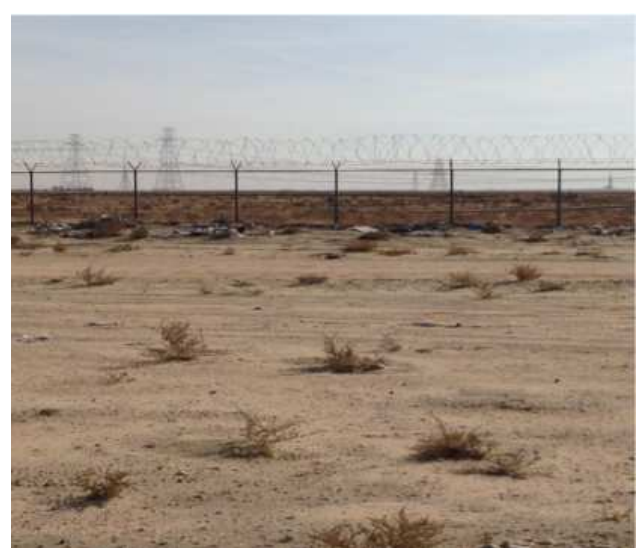

(B)

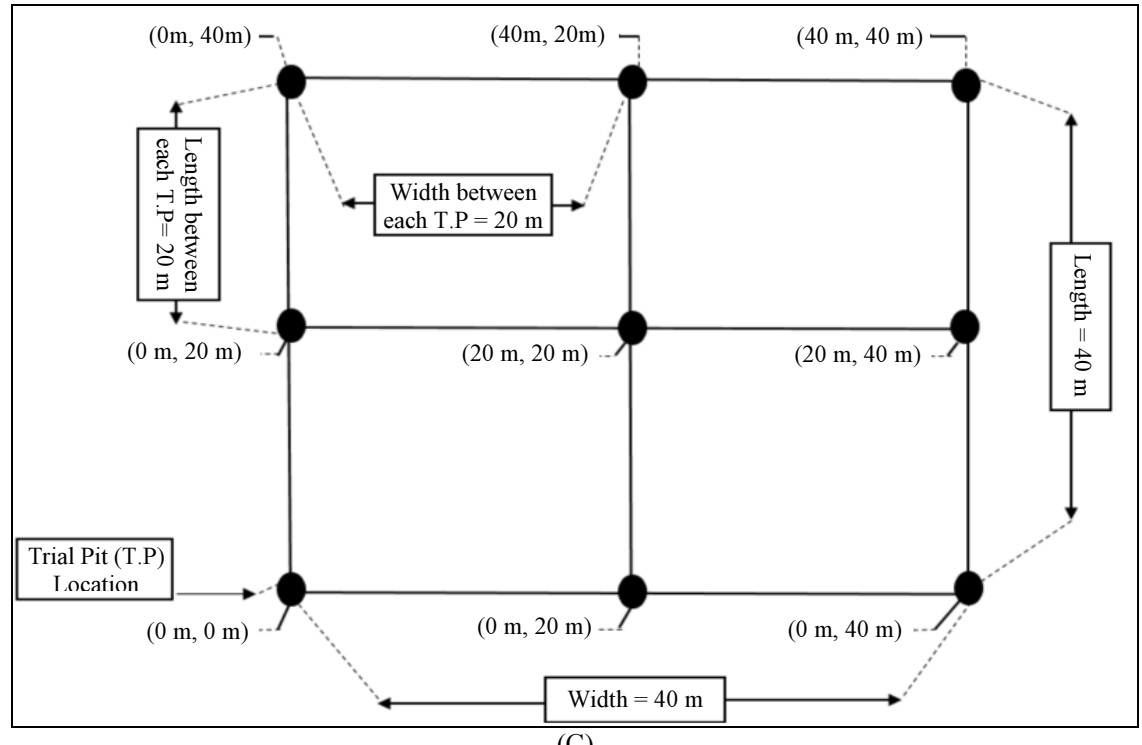

(C)

Fig. 3: Indicating potentially contaminated (A) and non-contaminated (B) sites and plan of T.Pslocations (applying to both sites) for samples (C) at Al-Ahmadi Oil Field

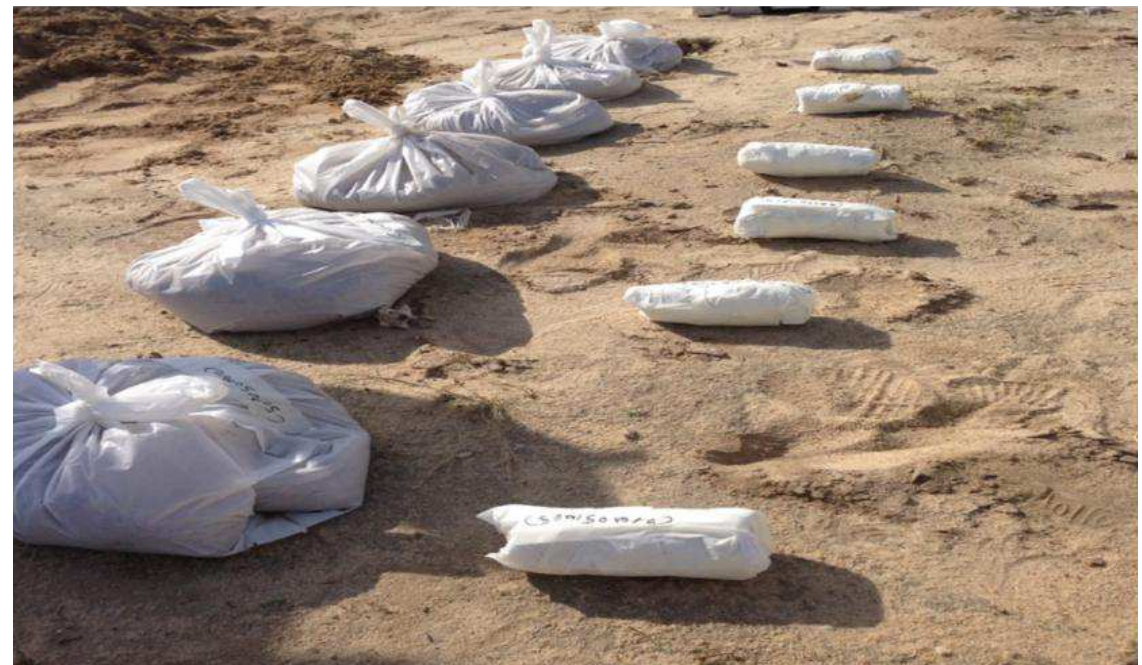

Fig. 4: Undisturbed and disturbed samples 


\section{Program and Procedure of Laboratory Testing}

Sand samples from both sites were subjected to laboratory testing including those for petroleum hydrocarbon along with both physical and strength tests.

\section{Petroleum Hydrocarbon Test}

A number of tests were conducted in order to determine the hydrocarbon concentration (Total Petroleum Hydrocarbon or TPH) in contaminated samples. Tests included Accelerated Solvent Extraction (ASE) and Gas Chromatography Mass Spectrometry (GCMS) which were utilised in order to convert the solid phase soil samples to liquid phase and to quantify the TPH concentration. All of these tests are explained in more detail in the subsequent sections.

\section{Hydrocarbon Extraction Test}

A Dionex-ASE-350 was used so as to separate the oil from the polluted sand specimen. specimens were transferred for examination of the weight of dry and during this phase, $3 \mathrm{~g}$ of disturbed sample soils from both contaminated and non-contaminated sites were blended with an equivalent volume of drying agent namely Earth of Diatomaceous (Thermo Scientific, USA) and packed among sand of acid washed (BDH, USA) and filters of cellulose (Dionex, UK) in an extraction cell before being placed on the device. These extraction processes were finished based on Method324 (Dionex, 2011).

Once the extraction process had been undertaken, each specimen was placed in a $50 \mathrm{ml}$ flask and $3 \mathrm{~g}$ of activated silica gel was added to avoid any impact on the GC column. To prevent the possibility of any obstruction to the GC column, the sample was filtered using $0.45 \mu \mathrm{m}$ gauge Chromacol filters once polar compounds had been removed. A three-hour settling period was then observed, to allow the silica gel to drop to the bottom of the sample so that the just the upper fluid content layer could be removed and placed into a beaker. The last stage of the process was to use heat and nitrogen to evaporate the liquid down to $1 \mathrm{ml}$, using the Turbo Evaporator (EQP-11, Athena technology). The resulting sample could then be transferred to the GC column for GC-MS analysis.

\section{Gas Chromatography Mass Spectrometry (GCMS) Test}

So as to measure the Total Petroleum Hydrocarbon (TPH) content in contaminated sample, TPH was further analysed by a GC-MS test in accordance with the method used by the author (Aldaihani, 2017).

As it is expressed in $(\mathrm{mg} / \mathrm{g})$, TPH concentration was computed based on the following equations:

$$
\begin{aligned}
& \text { - } \frac{\text { Dryweight }}{\text { Wetweight }} \times 100=\text { Dry mass }(\%) \\
& \text { - } \frac{\text { Netweight } \times \text { Drymass }}{100}=\text { Dry weight of soil (actual } \\
& \text { used in } A S E) \\
& \text { - } \frac{T P U\left(\frac{\mu g}{m l}\right) \text { obtained from the integration }}{\text { Dryweight of soil used }} \times 1000=T P H \\
& \text { dry of dry soil }(\mathrm{mg} / \mathrm{g})
\end{aligned}
$$

\section{Physical Tests}

Physical tests such as the Atterberg limits and Particle Size Distribution (PSD) were carried out for each of the samples based on the methods described by ASTM D-422 (1998) and ASTM D-4318 (1995), respectively.

\section{Strength Test}

To ensure the samples were of the same natural density as if they had not been extracted or moved from the test site, they were each compressed into $18 \mathrm{~mm}$-high round chambers measuring $63 \mathrm{~mm}$ across. Using MATEST equipment featuring a mechanical loading system, direct shear tests were carried out according to ASTM D-3080 (1998).

\section{Results and Discussion}

\section{Soil Hydrocarbon Characterization}

Table 1 sets out the results of the GCMS test, which show the TPH concentrations $(\mathrm{mg} / \mathrm{kg})$ detected in nine contaminated and non-contaminated samples.

The results in this Table were obtained from an analysis of chromatogram curves via a GC-MS instrument (Fig. 5). This chromatogram shows results for one of the detected samples in the contaminated site. No TPH was found from the non-contaminated site, evidencing the absence of hydrocarbon contamination, which meant that it can be considered a control site against which other samples can be benchmarked (Table 1). From the previous Table, it was noted that the TPH concentration was $1685 \mathrm{mg} / \mathrm{kg}$ which represents a contamination percentage of 0.657 .

There was no clear data to determine the contamination content in the selected site during 1990, but the tested area is expected to be within highly contaminated zones. The very low current TPH concentration clearly reveals the effect of ageing on contamination concentration and could be attributed to the evaporative effect of arid conditions in Kuwait over the last 26 years. The effect of biodegradation might also be considered, although this is not widely regarded as high within the Kuwaiti environment. 


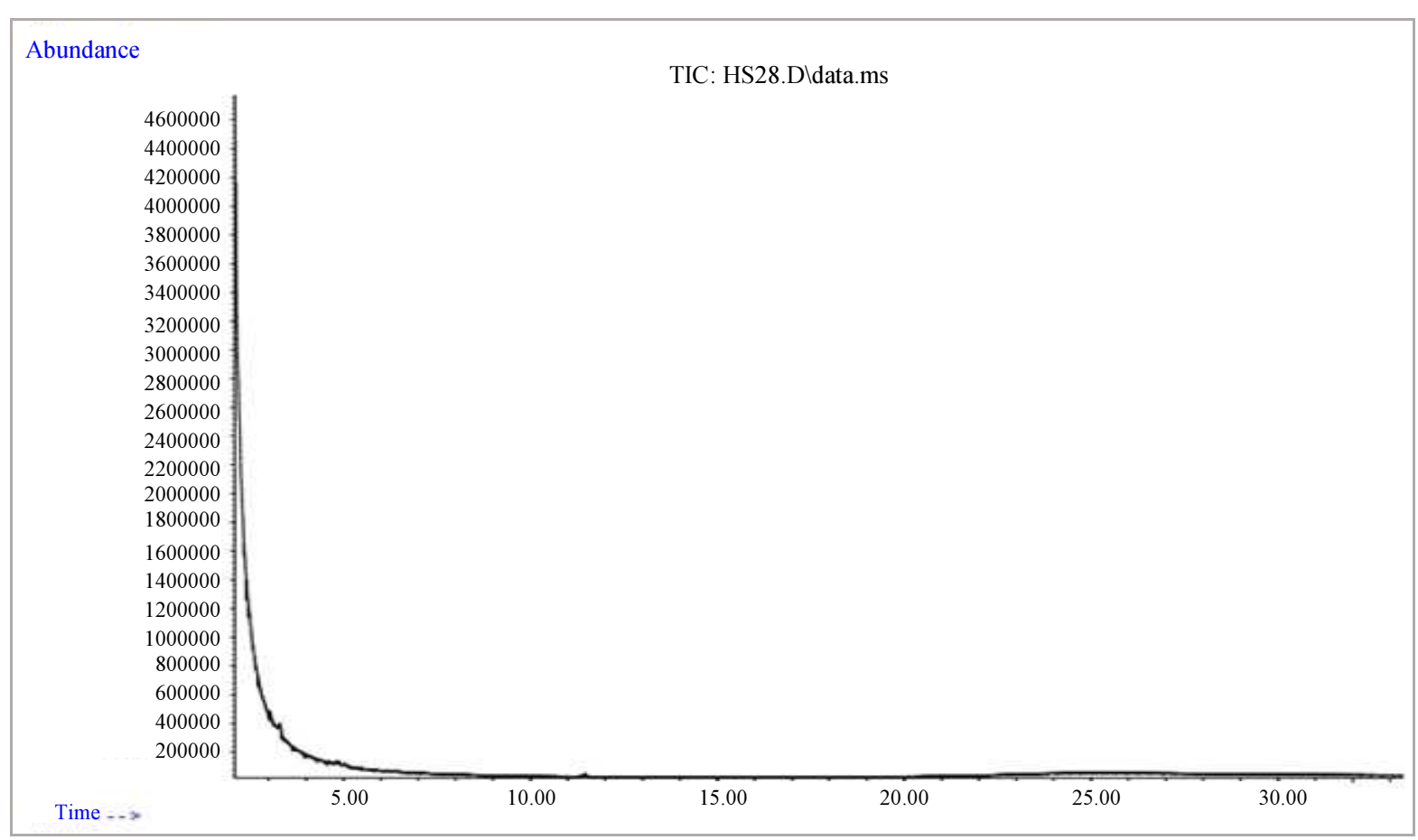

(A)

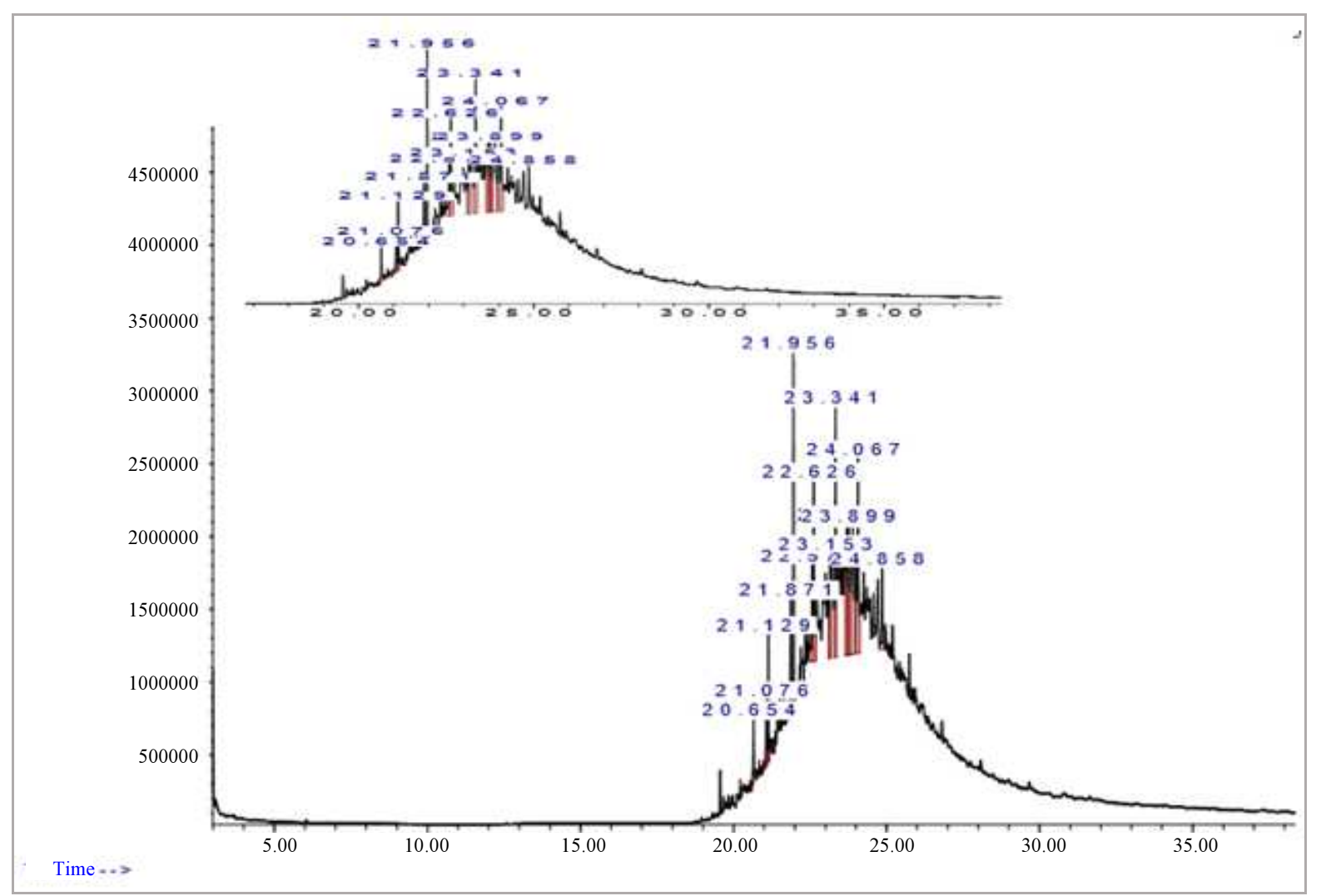

(B)

Fig. 5: An example of Total Ion Chromatograms (TIC) of T.P.C (40 m, $40 \mathrm{~m})$ at non-contaminated (A) and contaminated (B) samples with TPH 
Particle size distrbution curve for soil samples at non contaminated site

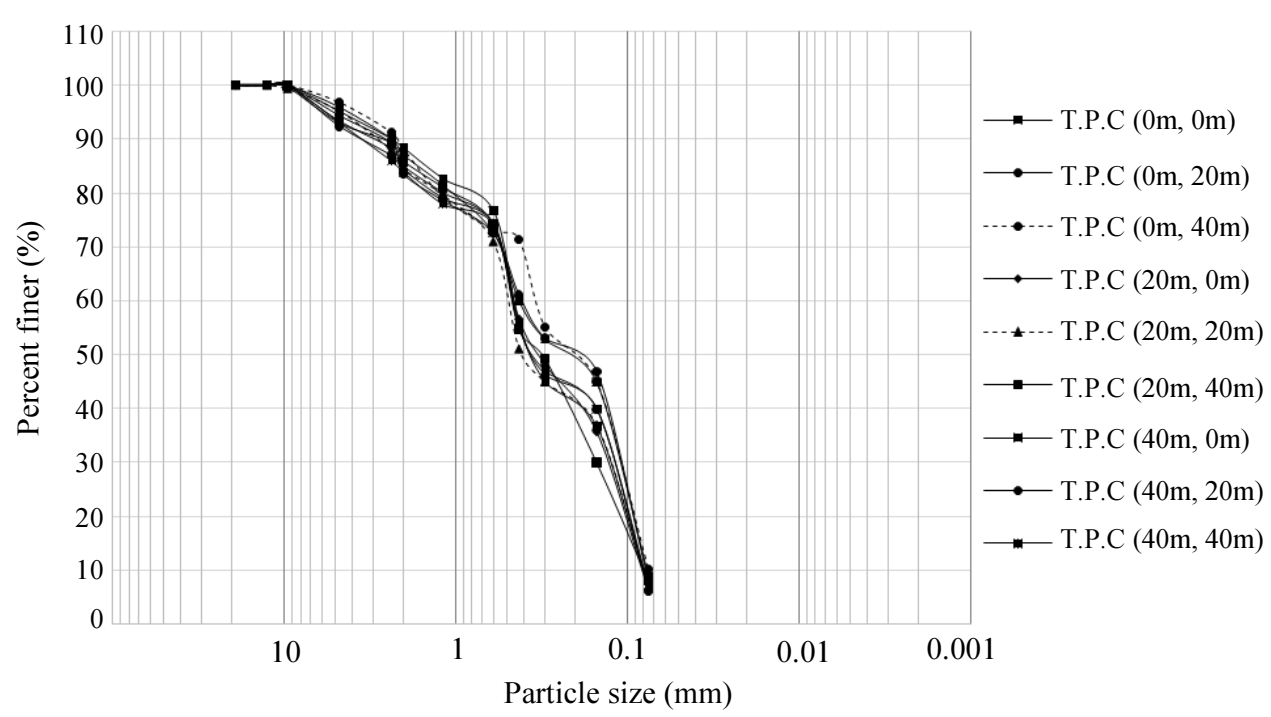

(A)

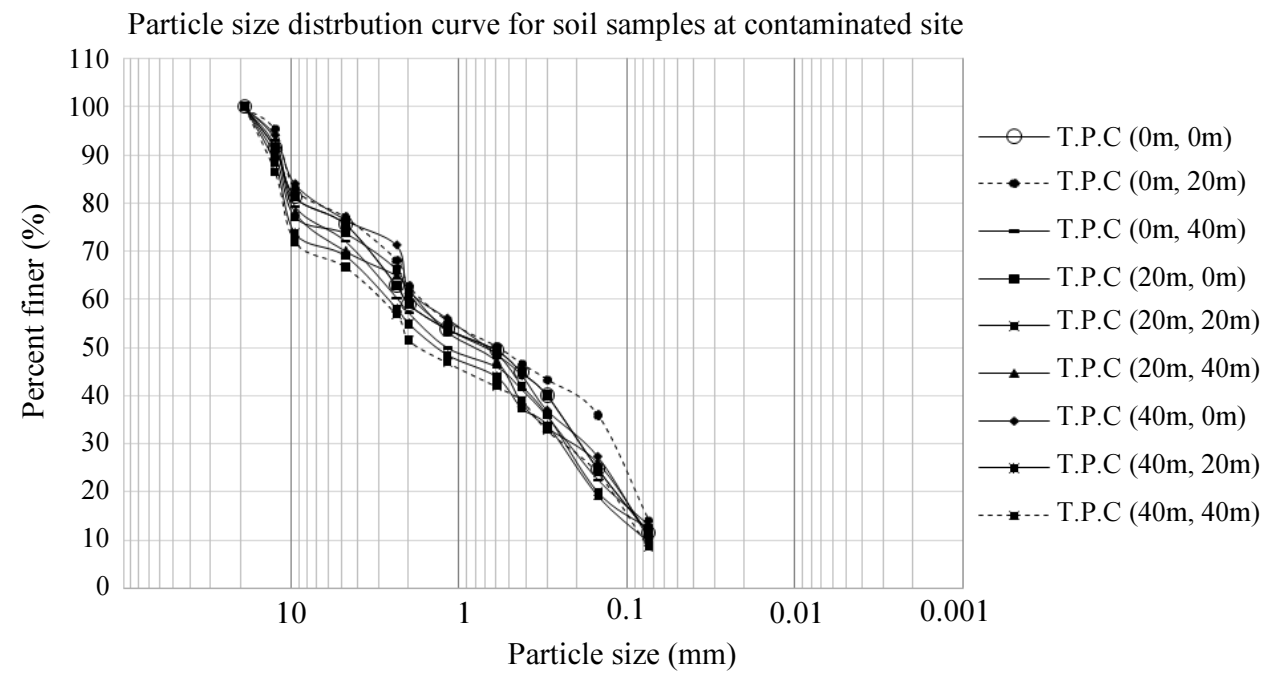

(B)

Fig. 6: PSD Curves for non-contaminated (A) and contaminated (B) samples at depth $(30 \mathrm{~cm})$

Table 1: Analysis of TPH of the oil-contaminated and non-contaminated samples

\begin{tabular}{|c|c|c|c|c|c|c|}
\hline \multirow[b]{2}{*}{ Samples T.P.Cs. } & \multicolumn{3}{|c|}{ Contaminated site } & \multicolumn{3}{|c|}{ Non-contaminated site } \\
\hline & $\begin{array}{l}\text { Sample } \\
\text { number }\end{array}$ & $\begin{array}{l}\text { Sample } \\
\text { mass }(\mathrm{g})\end{array}$ & $\begin{array}{l}\text { TPH concentration } \\
(\mathrm{mg} / \mathrm{kg})\end{array}$ & $\begin{array}{l}\text { Sample } \\
\text { number }\end{array}$ & $\begin{array}{l}\text { Sample } \\
\text { Mass (g) }\end{array}$ & $\begin{array}{l}\text { TPH concentration } \\
(\mathrm{mg} / \mathrm{kg})\end{array}$ \\
\hline$(0 \mathrm{~m}, 0 \mathrm{~m})$ & 1 & 10.03 & 1570 & 1 & 10.02 & $*$ N.D \\
\hline$(0 \mathrm{~m}, 20 \mathrm{~m})$ & 1 & 10.02 & 2000 & 1 & 10.01 & \\
\hline$(0 \mathrm{~m}, 40 \mathrm{~m})$ & 1 & 10.02 & 2020 & 1 & 10.01 & \\
\hline$(20 \mathrm{~m}, 0 \mathrm{~m})$ & 1 & 10.03 & 3000 & 1 & 10.04 & \\
\hline$(20 \mathrm{~m}, 20 \mathrm{~m})$ & 1 & 10.01 & 2500 & 1 & 10.03 & \\
\hline$(20 \mathrm{~m}, 40 \mathrm{~m})$ & 1 & 10.00 & 1800 & 1 & 10.03 & \\
\hline$(40 \mathrm{~m}, 0 \mathrm{~m})$ & 1 & 10.02 & 1100 & 1 & 10.01 & \\
\hline$(40 \mathrm{~m}, 20 \mathrm{~m})$ & 1 & 10.04 & 1240 & 1 & 9.99 & \\
\hline$(40 \mathrm{~m}, 40 \mathrm{~m})$ & 1 & 10.02 & 1350 & 1 & 10.02 & \\
\hline $\begin{array}{l}\text { Mean value of } \\
\text { TPH (mg/kg) }\end{array}$ & & 1658 & & & $*$ N.D & \\
\hline
\end{tabular}

Note: $*$ N.D $=$ Not Detected with TPH 


\section{Soil Physical Properties}

\section{Atterberg Limits}

As anticipated, results confirm that hydrocarbon contamination has no impact on the Atterberg limited. This is due to the fact that the soil was sand-based, making it naturally non-plastic. All stages of the petroleum-based contaminants - in any form - are known to be hydrophobic and therefore would not affect any changes to this sandy soil's level of plasticity.

\section{Particle Size Distribution (PSD)}

Figures 6 and 7 shows the outcomes from PSD testing of the samples taken from the contaminated oil lake and the uncontaminated sites. The highest and lowest levels of PSD can be readily identified (and are represented in different colours), but because there are so many lines showing the multiple samples taken from various Trial Pit Co-ordinates (T.P.Cs.), it is not easy to read each one individually.

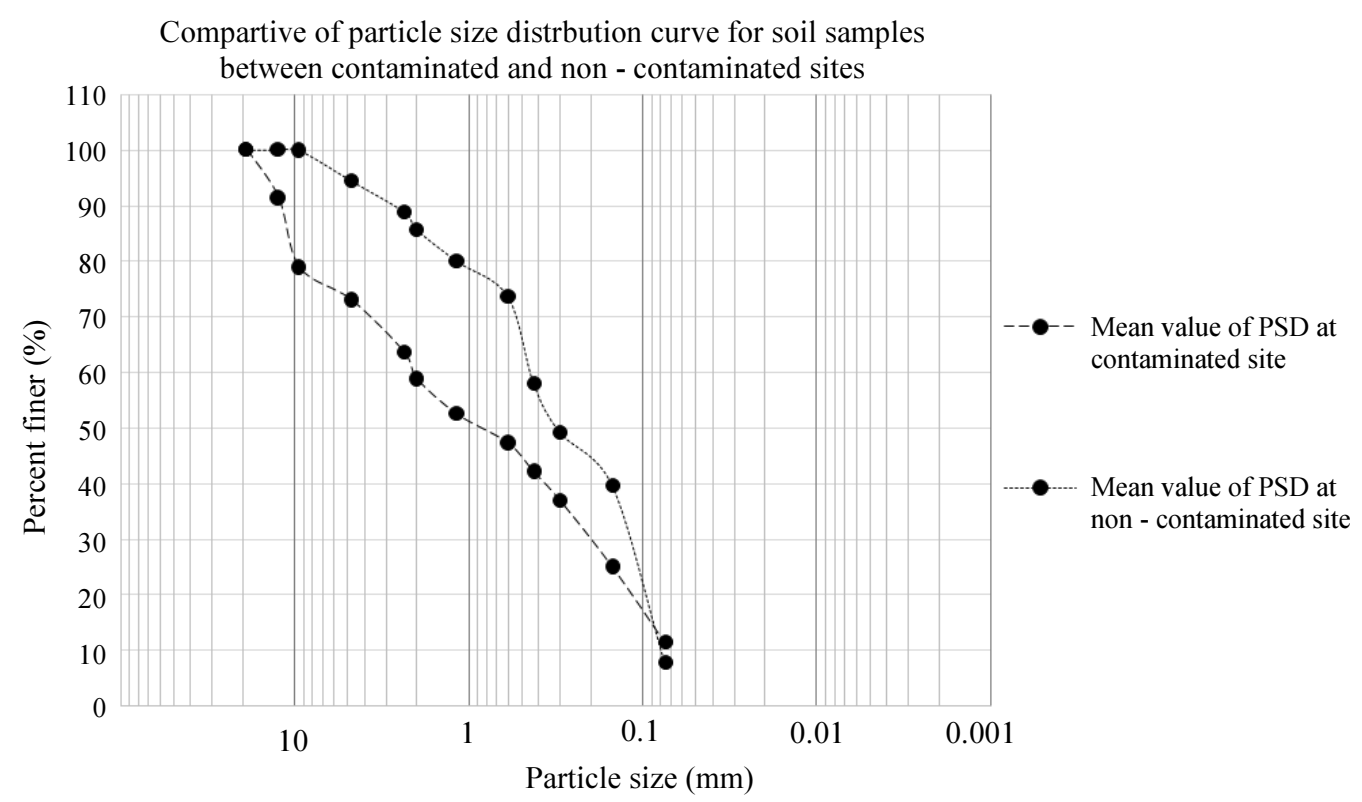

Fig. 7: A comparative for the PSD values for non-contaminated and contaminated samples at depth $30 \mathrm{~cm}$

Table 2: Comparing of soil constituents in contaminated and non-contaminated samples at depth $(30 \mathrm{~cm})$

\begin{tabular}{|c|c|c|c|c|c|c|c|c|}
\hline \multirow[b]{2}{*}{ Samples T.P.Cs. } & \multicolumn{8}{|c|}{ Soil classification (\%) at contaminated site } \\
\hline & Silty clay & Fine sand & Medium sand & Coarse sand & Fine gravel & Coarse gravel & Exact soil & S.G* \\
\hline$(0 \mathrm{~m}, 0 \mathrm{~m})$ & 13.0 & 22.0 & 5.0 & 18.0 & 32.0 & 0 & 12.7 & Sand with silt \\
\hline$(0 \mathrm{~m}, 20 \mathrm{~m})$ & 14.0 & 32.0 & 16.0 & 14.0 & 23.0 & 0 & 14.3 & \\
\hline$(0 \mathrm{~m}, 40 \mathrm{~m})$ & 13.0 & 28.0 & 16.0 & 15.0 & 28.0 & 0 & 13.2 & \\
\hline$(20 \mathrm{~m}, 0 \mathrm{~m})$ & 12.0 & 33.0 & 14.0 & 17.0 & 24.0 & 0 & 11.8 & \\
\hline$(20 \mathrm{~m}, 20 \mathrm{~m})$ & 13.0 & 30.0 & 19.0 & 13.0 & 26.0 & 0 & 12.5 & \\
\hline$(20 \mathrm{~m}, 40 \mathrm{~m})$ & 11.0 & 27.0 & 24.0 & 8.0 & 30.0 & 0 & 11.3 & \\
\hline$(40 \mathrm{~m}, 0 \mathrm{~m})$ & 11.0 & 34.0 & 18.0 & 15.0 & 23.0 & 0 & 10.5 & \\
\hline$(40 \mathrm{~m}, 20 \mathrm{~m})$ & 10.0 & 28.0 & 18.0 & 14.0 & 31.0 & 0 & 9.7 & \\
\hline$(40 \mathrm{~m}, 40 \mathrm{~m})$ & 9.0 & 30.0 & 13.0 & 15.0 & 33.0 & 0 & 8.7 & \\
\hline Mean value & 11.8 & 29.3 & 15.9 & 14.3 & 27.8 & 0 & 11.6 & \\
\hline \multicolumn{9}{|c|}{ Soil classification (\%) at non-contaminated site } \\
\hline$(0 \mathrm{~m}, 0 \mathrm{~m})$ & 7.0 & 49.0 & 33.0 & 7.0 & 5.0 & 0 & 7.0 & Sand with silt \\
\hline$(0 \mathrm{~m}, 20 \mathrm{~m})$ & 8.0 & 53.0 & 22.0 & 11.0 & 6.0 & 0 & 8.0 & \\
\hline$(0 \mathrm{~m}, 40 \mathrm{~m})$ & 10.0 & 61.0 & 17.0 & 9.0 & 3.0 & 0 & 10.2 & \\
\hline$(20 \mathrm{~m}, 0 \mathrm{~m})$ & 7.0 & 50.0 & 28.0 & 8.0 & 7.0 & 0 & 6.5 & \\
\hline$(20 \mathrm{~m}, 20 \mathrm{~m})$ & 7.0 & 44.0 & 33.0 & 11.0 & 5.0 & 0 & 7.1 & \\
\hline$(20 \mathrm{~m}, 40 \mathrm{~m})$ & 8.0 & 47.0 & 31.0 & 7.0 & 7.0 & 0 & 8.1 & \\
\hline$(40 \mathrm{~m}, 0 \mathrm{~m})$ & 9.0 & 51.0 & 27.0 & 9.0 & 4.0 & 0 & 9.1 & \\
\hline$(40 \mathrm{~m}, 20 \mathrm{~m})$ & 6.0 & 49.0 & 29.0 & 8.0 & 8.0 & 0 & 6.3 & \\
\hline$(40 \mathrm{~m}, 40 \mathrm{~m})$ & 8.0 & 48.0 & 29.0 & 9.0 & 7.0 & 0 & 7.5 & \\
\hline Mean value & 7.8 & 50.2 & 27.7 & 8.8 & 5.8 & 0 & 7.8 & \\
\hline
\end{tabular}

Note: $*$ S.G $=$ Symbol Group of soil based on (ASTM D-422, 1998) 
However, it can be seen from the PSD lines that overall there were significant variations between contaminated samples taken at the same depth from different T.P.Cs. The range of graduation was much smaller for non-contaminated samples taken at the same depth (Fig. 6 and 7). This wide range in contaminated sample levels could have been caused by the varying ground level underneath the oil pool before it began to evaporate, which would have meant deeper levels of oil spill in the areas of lower ground and therefore potentially increasing contamination in this areas.

Table 2 compares samples from the contaminated and non-contaminates areas in terms of soil class, by showing the average (mean) calculated percentage values at a depth of $30 \mathrm{~cm}$, equivalent to topsoil. These mean values show a significant difference between the two sites: $5.8 \%$ for uncontaminated soil and $27.8 \%$ for contaminated soil. This difference in size could be caused by two possible factors: - the aggregation of particles due to the cementation action of hydrocarbons and residues from the hydrocarbons themselves. This aggregation reduced sand contents, which is shown clearly in the Table and has been revealed by other researchers including Taqieddin (2017).

It can also be seen that the contaminated site samples have higher average percentage sizes for the smaller grains (passing No. \# 200) than can been seen in the samples from the non-contaminated site. The higher fine percentages in the contaminated samples - an increase from $7.8 \%$ to $11.8 \%$ - are due to the drying of hydrocarbon forming small, asphaltene particles. This increase in the asphaltene content in the contaminated soil may be incorrectly attributed to increase the fine gradation content. These results showed clearly that the ageing effect is contradicted, with several studies carried out on laboratory-prepared contaminated soils (Taqieddin, 2017).

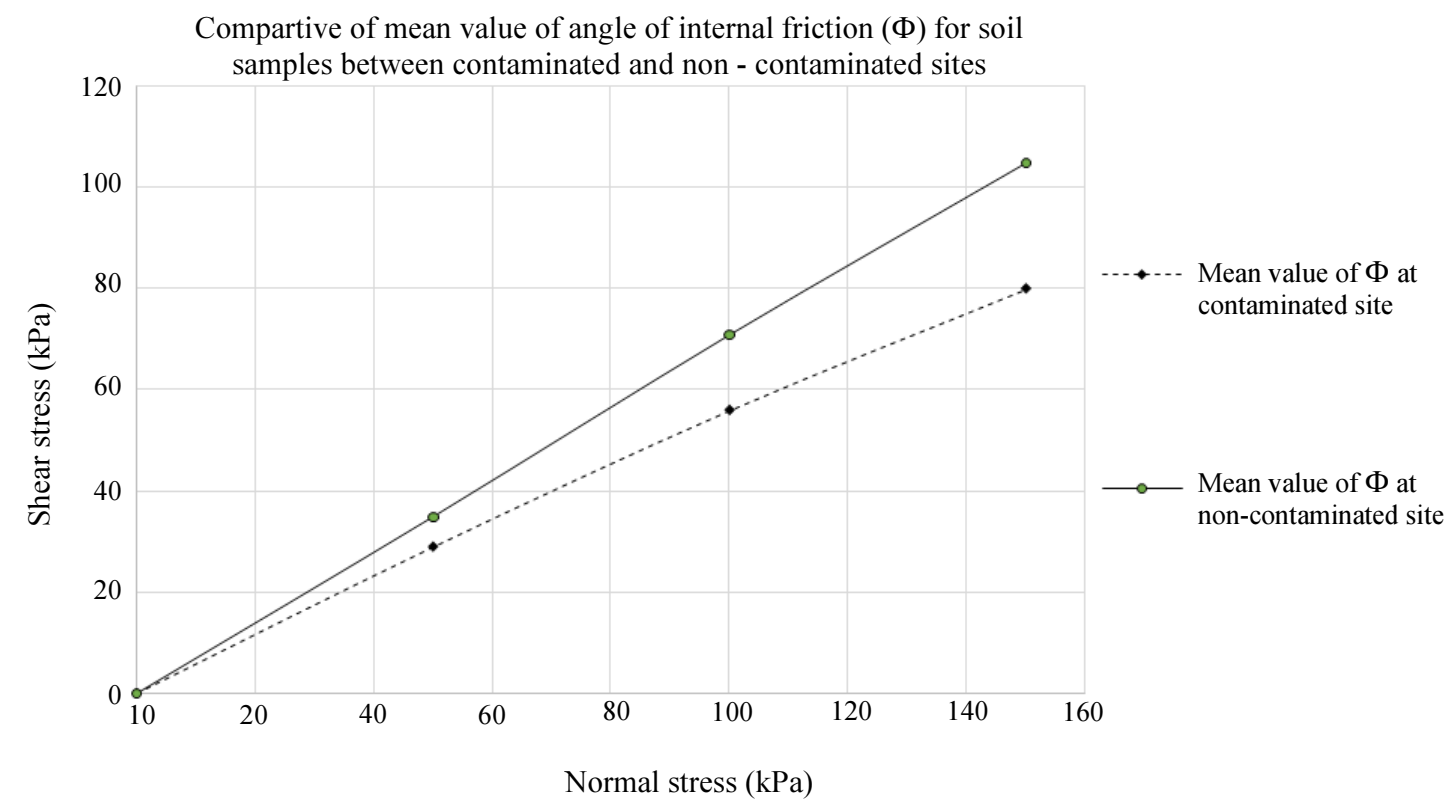

Fig. 8: Comparing the $\varphi$ values for contaminated and non-contaminated samples at top soil (i.e., $30 \mathrm{~cm})$

Table 3: Comparing of the $\varphi$ for contaminated and non-contaminated samples at depth $30 \mathrm{~cm}$

\begin{tabular}{lll}
\hline Samples T.P.Cs. & $\varphi$ At contaminated site & $\varphi$ At non-contaminated site \\
\hline$(0 \mathrm{~m}, 0 \mathrm{~m})$ & 27.0 & 36.0 \\
$(0 \mathrm{~m}, 20 \mathrm{~m})$ & 26.0 & 36.3 \\
$(0 \mathrm{~m}, 40 \mathrm{~m})$ & 27.0 & 37.0 \\
$(20 \mathrm{~m}, 0 \mathrm{~m})$ & 28.0 & 35.0 \\
$(20 \mathrm{~m}, 20 \mathrm{~m})$ & 27.0 & 35.6 \\
$(20 \mathrm{~m}, 40 \mathrm{~m})$ & 26.0 & 36.0 \\
$(40 \mathrm{~m}, 0 \mathrm{~m})$ & 25.0 & 36.1 \\
$(40 \mathrm{~m}, 20 \mathrm{~m})$ & 28.0 & 35.0 \\
$(40 \mathrm{~m}, 40 \mathrm{~m})$ & 27.0 & 37.0 \\
Mean value & 26.8 & 36.0 \\
\hline
\end{tabular}




\section{Shear Strength Properties}

Figure 8 displays the outcomes of test of direct shear strength for contaminated and non-contaminated sandy soils. In addition, the results of direct shear strength test (i.e., $\varphi$ and c parameters) are summarised in Table 3.

The (c) for all samples for both areas were zero, which indicates that cohesion in sandy types of soil is not generated by this level of hydrocarbon contamination. The cohesion value results for the contaminated soil contradict with those obtained from laboratory mixed outcomes values (Taqieddin, 2017; AlAdili et al., 2017; Chaudhary and Singh, 2016). It is possible that this could be attributed to the effect of ageing that eliminates the impact of cohesion seen in previous studies. In addition to the effect of biodegradation, the arid climate in Kuwait may also reduce the absorbed layer thickness of the soil particles.

Hydrocarbon contamination led to the angle of internal friction being steadily and recognizably decreased in all samples. At the contaminated site, the mean value of TPH concentration $(\mathrm{mg} / \mathrm{kg})$ was 1658 $\mathrm{mg} / \mathrm{kg}$ and was undetectable at the non-contaminated area. With reference to the mean value of $(\varphi)$, these reduced from 36 at the non-contaminated site to 26.8 at the contaminated site. It is possible that weak accumulation of sand particles in ground layer might explain this reduction in angle of internal friction $(\varphi)$. The increase in fine content due to asphalting in part of the ageing effect and may be responsible for the weak bonding between soil particles. Similar findings were published by several researchers including Shin et al. (1999), Khamehchiyan et al. (2007), Singh et al. (2009), Chaudhary and Singh (2016), Taqieddin (2017) and AlAdili et al. (2017).

\section{Conclusion}

The objective of this study was to investigate the long term ageing effect of oil pollution on behavior of physical and shear strength soil properties. Using sandy soil samples from the oil-contaminated Al-Ahmadi area in Kuwait, laboratory tests were carried out on contaminated and non-contaminated soil samples.

Tests including particle size distribution, Atterberglimits and Petroleum hydrocarbon were carried out, as well as analysing the effect of direct shear strength on the soil samples. The findings revealed the following:

- Very low Total Petroleum Hydrocarbon (TPH) in the tested zone: It was noted that the TPH concentration was $1685 \mathrm{mg} / \mathrm{kg}$ which represents a contamination percentage of 0.657 . This very low TPH concentration showed clearly the ageing effect of oil on contaminated soil in the 28 years since contamination occurred. This took into account the variations in oil content due to the weathering effects of the very hot Kuwait climate, where ambient summer temperatures reach $50^{\circ} \mathrm{C}$, as well as the effect of the climate on biodegradation (although the latter was not considered a major factor)

- Impact of long-term contamination on the distribution of grain sizes: Within the sandy topsoil layer, the average particle size values rose from a mean $5.8 \%$ to $27.8 \%$ following contamination - an increase of over $4.75 \mathrm{~mm}$. This was due to the aggregation of grains caused by hydrocarbons. Finer particles (under $0.075 \mathrm{~mm}$ ) also increased from a mean $7.8 \%$ to $11.8 \%$ after contamination. These changes resulted in a detrimental effect on the soil's granularity.

- Impact of long-term contamination on the angle of internal friction: There was a postcontamination reduction in the angle of internal friction as a result of soil particle aggregation. As well as having a lower PSD, the soil as also seen an increase to the ageing effect. This is, due to the increase in levels of finer content caused by higher levels of asphalting, which in turn can lead to a reduction in adhesion between particles

\section{Further Work}

- The soil in Kuwait varies in its chemical composition and the level to it has been contaminated, so it is recommended that more testing is undertaken before the use of contaminated soil is considered possible

- These studies should investigate on different geotechnical soil properties such as Permeability, Compaction, Consolidation, compressibility

- Further investigation into changes to the grain particles related to contact with oil contaminated via scanning electronic microscopy

\section{Acknowledgment}

The Authors would like to acknowledge the support of the Kuwait Oil Company (KOC) and Kuwait institution for Research Scientifics (KISR).

\section{Author's Contributions}

Humoud Melfi Aldaihani: Soil samples collection, experimental setup, samples testing and writing the manuscript.

Fahad A. Alotaibi: Inspect samples in laboratory, design the results analysis and writing the manuscript.

\section{Ethics}

This article is original and contains unpublished material. It is confirmed that all authors have read and approved the manuscript and there are no ethical issues involved. 


\section{References}

Al-Awadhi, N., R. Al-Daher, A. El-Nawawy and M.T. Baiba, 1996. Bioremediation of oil-contaminated soil in Kuwait, land farming to remediate oilcontaminated soil. Soil Sediment Contaminat., 5: 243-260. DOI: 10.1080/15320389609383528

A1-Awadhi, N., K.J. Williamson and J.D. Isok, 1993. Remediation of Kuwait's Oil Contaminated Soils. In: Hydrocarbon Contaminated Soil and Groundwater, Kostecki, P.T. and E.J. Calabrese (Eds.), Lewis Publisher, London, pp: 9-21.

Al-Awadhi, N., M.S. Abdal, E.J. Briskey and K. Williamson, 1992. Assessment of technologies for the remediation of oil-contaminated soil resulting from exploded oil wells and burning oil fires in Kuwait. Proceedings of the 85th Annual Meeting on the Air and Waste Management Association Meeting, Jun. 21-26, Pittsburgh, PA, pp: 211-211.

Al-Adili, A., K.Y. Alsoudany and A. Shakir, 2017. Investigation of crude oil pollution effect on stiffness characteristics of sandy and gypseous soil. Soil Mechan. Foundat. Eng., 54: 276-282.

DOI: $10.1007 / \mathrm{s} 11204-017-9469-\mathrm{x}$

Al-Besharah, J., 1991. The Kuwait oil fires and oil lakesfacts and numbers. Proceedings of the Environmental and Health Impact of the Kuwaiti Oil Fires, (KOF' 91), University of Birmingham, Birmingham, UK, pp: 12-15.

Aldaihani, H.M., F.A. Alotaibi and F.F. Al-ajmi, 2018. Grain size distribution characteristics variation in oily contaminated sandy soils due to long term aging effect in Al-Ahmadi field at Kuwait. Am. J. Applied Sci., 15: 464-475.

Aldaihani, H.M.Z., 2017. A geotechnical, geochemical and human health risk assessment of a dry oil lake site in Kuwait. PhD Thesis, University of Portsmouth, Portsmouth, U.K.

Al-Duwaisan, D.B. and A.A. Al-Naseem, 2011. Characterization of oil contaminated soil Kuwait oil lakes. Proceedings of 2nd International Conference on Environmental Science and Technology, (EST' 11), IACSIT Press, Singapore, pp: 439-442.

Al-Sanad, H.A. and N.F. Ismael, 1997. Ageing effects on oil-contaminated Kuwaiti sand. J. Geotech. Geoenviron. Eng., 123: 290-293.

DOI: 10.1061/(ASCE)1090-0241(1997)123:3(290)

Al-Sanad, H.A., W.K. Eid and N.F. Ismael, 1995. Geotechnical properties of oil contaminated Kuwaiti sand. J. Geotech. Eng., 121: 407-412.

DOI: 10.1061/(ASCE)0733-9410(1995)121:5(407)
ASTM D 2937-04, 2008. Standard test method for density of soil in place by the drive-cylinder method report No. D 2937-04. ASTM, West Conshohocken, Philadelphia $(\mathrm{Pa})$, USA.

ASTM D 4220-95, 2000. Standard practices for preserving and transporting soil samples report No. D 4220-95. ASTM, West Conshohocken, Philadelphia (Pa), USA.

ASTM D-3080, 1998a. D-3080 annual book of ASTM standards, standard test method for direct shear test of soils under consolidated drained condition. ASTM, West Conshohocken, Philadelphia (Pa), USA.

ASTM D-422, 1998. D-422 annual book of ASTM standards, standard test method for particle-size analysis of soils. ASTM, West Conshohocken, Philadelphia (Pa), USA.

ASTM D-4318, 1995. D-4318 annual book of ASTM standards, standard test method for liquid limit, plastic limit and plasticity index of soils. ASTM, West Conshohocken, Philadelphia (Pa), USA.

Asem, S.O., R.F. Misak, A. Alenezi, W.Y. Roy and S.A. Shahid et al., 2016. Effects of crude oil on some soil types of Kuwait. Kuwait J. Sci., 43: 150-161.

Chaudhary, A. and A. Singh, 2016. Study of behavioural change in the soil contaminated with petrol. Civil Environ. Eng., 6: 1-3.

DOI: $10.4172 / 2165-784 X .1000217$

Cho, B., H. Chino, H. Tsuji, T. Kunito and K. Nagaoka et al., 1997. Laboratory-scale bioremediation of oilcontaminated soil of Kuwait with soil amendment materials. J. Chemosphere, 35: 1599-1611. DOI: $10.1016 / \mathrm{S} 0045-6535(97) 00220-8$

Dionex, 2011. Accelerated Solvent Extraction (ASE) of hydrocarbon contaminants (BTEX, Diesel and TPH) in soils (application note 324). Thermo Fisher Scientific, Salt Lake City, UT, USA.

El-Baz, F., A. Abuelgasim, M. Koch, M. Pax-Lenney and E. Lambin et al., 1994. Detection by Satellite Images of Environmental Change Due to the Gulf War. In: The Gulf War and the Environment, ElBaz, F. and R.M. Makharita (Eds.), Gordon and Breach Science, Lausanne, pp: 1-24.

Karkusha, M.O. and Z. Abdul Kareemb, 2017. Investigation the impacts of fuel oil on the geotechnical properties of cohesive soil. Eng. J., 21: 128-137. DOI: 10.4186/ej.2017.21.4.127

Khamehchiyan, M., A.H. Charkhabi and M. Tajik, 2007. Effects of crude oil contamination on geotechnical properties of clayey and sandy soils. Eng. Geol., 89: 220-229. DOI: 10.1016/j.enggeo.2006.10.009

Landon, M.M., 2007. Development of non-destructive sample quality assessment method for soft clays. $\mathrm{PhD}$ Thesis, University of Massachusetts Amherst, USA. 
Shin, E.C., J.B. Lee and B.M. Das, 1999. Bearing capacity of a model scale footing on crude oilcontaminated sand. Geotech. Geol. Eng., 17: 123-132. DOI: $10.1023 / \mathrm{A}: 1016078420298$

Singh, S.K., R.K. Srivastava and S. John, 2009. Studies on soil contamination due to used motor oil and its remediation. Canad. Geotech. J., 46: 1077-1083. DOI: $10.1139 / \mathrm{T} 09-047$
Taqieddin, S.A., 2017. Effect of diesel-oil contamination on shear strength and compressibility behavior of sandy soil. Jordan J. Civil Eng., 11: 607-613. 